\title{
Few useful websites on radiation and radiation safety
}

\author{
IK Indrajit \\ Department of Radiology, Command Hospital (Air Force), Bangalore - 560 007, India \\ Correspondence: I. K. Indrajit, Department of Radiodiagnosis and Imaging, Command Hospital (Air Force), Bangalore - 560 007, India. \\ E-mail: inji63@gmail.com
}

1. International Commission on Radiological Protection (ICRP) at http://www.icrp.org/is a professional body created for providing information on the science of radiological protection. It puts forward recommendations and guidance on protection against ionizing radiation. An engaging 'Educational Area' at http://www.icrp.org/ educational_area.asp offers 'downloadable ICRP material aimed at promoting knowledge about radiological protection.' These include copyrighted material on Pregnancy and Medical Radiation, Interventional Radiology, Accidents in Radiotherapy, CT Dose Management and Digital Radiology. Similarly, the International Commission on Radiological Units and Measurements at http://www.icru.org/has material on current programs, reports, abstracts, news, etc.

2. National Council on Radiation Protection and Measurements at http://www.ncrponline.org/is a website that focuses on 'Informing the public about radiation exposure and protection.' The mission at NCRP is 'to formulate and widely disseminate information, guidance, and recommendations on radiation protection and measurements which represent the consensus of leading scientific thinking.' Sections are available dealing with publications, current programs, and news and events. The radiation safety issues for image-guided interventional medical procedures are available at http:// www.ncrponline.org/Current_Prog/SC_2-3.html.

3. The Atomic Energy Regulatory Board (AERB) is the competent authority in India for enforcing rules and regulations for safe use of ionizing radiation. Constituted on 15 Nov 1983, its mission as stated in its Web portal at http://www.aerb.gov.in/. 'is to ensure that the presence of ionizing radiation and the use of nuclear energy in India do not cause unacceptable impact on the health of workers, members of the public, and the environment.' In India, the AERB estimates that 'more than 35,000 medical X-ray machines are being used for the benefit of patients all over the country.' For purposes of their regulation and safe operation, the AERB has published three important documents, available at http://www.
aerb.gov.in/cgi-bin/X-Ray/XRAY.asp. These comprise: a) Atomic Energy (Radiation protection) Rules, 2004; b) Radiation Surveillance Procedures for Medical Applications of Radiation, 1989, and c) the AERB Safety Code on 'Medical Diagnostic X-Ray Equipment and Installation, 2001,' available at http://www.aerb.gov. in/t/xray/med-2.PDF. Importantly, all medical X-ray installations mandatorily require registration at AERB, the application forms for which can be downloaded from http://www.aerb.gov.in/t/xray/xrayregform.pdf.

4. Food and Drug Administration (FDA) at http://www. fda.gov/is responsible for 'protecting the public health by assuring the safety, efficacy, and security of human and veterinary drugs, biological products, medical devices, food supply, cosmetics, and products that emit radiation.' The radiation-related material are available in several sections. A useful starting point is Medical X-Rays at http://www.fda.gov/Radiation-EmittingProducts/ RadiationEmittingProductsandProcedures/ MedicalImaging/MedicalX-Rays/default.htm. CDRH organ dose handbooks are available that deal with reference values of radiation doses in pediatric radiology, mammography, diagnostic radiology projections, and upper GI fluoroscopy. Radiation Issues in CT Scan, a topic of immense concern, is accessible from http://www.fda.gov/Radiation-EmittingProducts/ RadiationEmittingProductsandProcedures/ MedicalImaging/MedicalX-Rays/ucm115317.htm.

5. American College of Radiology (ACR) offers a collection of guidelines and standards at http://www. acr.org/SecondaryMainMenuCategories/quality_safety/ guidelines/med_phys.aspx. Broadly, they serve as an 'educational tool designed to assist practitioners in providing appropriate radiologic care for patients.' Specific to the topic of radiation, the following ACR practice guidelines and technical standards are available: Diagnostic reference levels in medical X-ray imaging, diagnostic medical physics, performance monitoring of radiographic and fluoroscopic equipment, and management of the use of radiation in fluoroscopic procedures. 
6. The Alliance for Radiation Safety in Pediatric Imaging has launched an 'Image Gently Campaign' to increase the awareness of radiation effects related to pediatric CT scan referrals. Available at http://www.pedrad.org/associations/5364/ig/index. cfm? page $=388$, the 'Image Gently' Web portal has preliminary sections on Tests, Procedures, What can I do, Resources, FAQ, and International resources. There are downloadable informational brochures on 'What parents should know about CT scans for children' and 'What parents should know about medical radiation safety.' Similar to immunization records, the 'My child's medical imaging record' is a downloadable document 'for tracking the date, type of exam, and the place where the study was performed.'

7. Health Risks From Exposure To Low Levels Of Ionizing Radiation is a report rendered by the Biological Effects of Ionizing Radiation Committee (BEIR) is available from the National Academies Press, Washington, D.C. The current version of the report (BEIR VII), available at http://www.nap.edu/openbook. php?isbn $=030909156 \mathrm{X}$, reviews a range of issues: Evidence on basic biological and genetic concepts, molecular and cellular responses to ionizing radiation, and radiation-induced cancer mechanisms; there is also a series of medical, occupational, radiation, and environmental studies.

8. The Radiation Information Network at http://www. physics.isu.edu/radinf/from the Idaho State University, has sections on regulations, professional organizations, research, and education. A set of History of Radiation and Radiation Protection links is browsable at http://www. physics.isu.edu/radinf/hist.htm. Aleading section 'General Areas of History' has links to the first 50 years of radiation protection with a timeline, brief history of radiation, and a re-creation of the Curie experiment, to name a few. The section on notable people in the history of radiation has links to an electronic Nobel museum, a philatelic history of radiology, W. C. Roentgen, and the discovery of the X-ray.

9. A variety of Radiation Training/Safety Manuals are available on the net, of which few are reviewed here.

a. Diagnostic X-ray Safety Manual at http://safetyservices. ucdavis.edu/environmental-health-safety/radiological/ forms/forms-manuals-plans from University of California at Davis, deals with units of radiation measurement, biological effects of ionizing radiation, radiation exposure limits and comparisons, dosimetry, physics of X-ray production, and radiographic and fluoroscopic general safety protocols.

b. Caltech Radiation Safety Training Manual at http:// www.safety.caltech.edu/documents/78-radiation safety_training_manual.pdf is a guidebook from California Institute of Technology. The highlight of this manual is the various sections on radiation fundamentals, interaction of radiation with matter, activity, exposure, dose concepts, and radioactive waste disposal. Of interest are the sections on radiation safety for X-ray units and occupational dose limits.

c. Radiation Safety Manual from Environmental Health and Safety, Stanford University, California available at http://www.stanford.edu/dept/EHS/prod/aliases/ radmanual.html is an exhaustive radiation safety manual. Updated in 2007, there are dedicated subsections covering properties of radioactivity, interactions of radiation with matter, measurement of radiation, biological effects of radiation, and ALARA policy.

d. Other noteworthy manuals available online are sourced from Michigan State University Office of Radiation, Chemical and Biological safety at http://www.orcbs. msu.edu/radiation/programs_guidelines/radmanual/ radmanual.pdf, from Duke University electron laser laboratory at http://www.fel.duke.edu/contact/dfell_ rad_train_manual.pdf, and Navmed Radiation Health Protection Manual at http://fas.org/irp/doddir/milmed/ rhpm.pdf.

10. Review articles/citations on radiation: There are numerous articles on radiation available from various journals in Radiology and Medicine. From these, a handy list of articles recently published and available online, is given in Table 1 .

\section{End Piece}

WHO's Ionizing Radiation Programme at http://www.who. int/ionizing_radiation/en/has few brief sections on radiation accidents and emergencies, environmental radiation, and ionizing radiation. The radiation protection division of the independent UK organization Health Protection Agency, formerly called National Radiological Protection Board (NRPB) offers its salient publications at http://www.hpa. org.uk/HPA/Publications/Radiation/. Radiation Exposure in X-ray Examinations from the portal RadiologyInfo is available at http://www.radiologyinfo.org/en/safety/index. $\mathrm{cfm} ? \mathrm{pg}=$ sfty_xray.

Which Radiology Device is a hardware compendium from Radiology Device Reviews available at http://www. whichradiologydevice.com/forum.aspx?g = forum. The Web portal is an offshoot from Which Interventional Device at http://www.whichinterventionaldevice.com/. The site has many practice-based sections dealing with specialities, product categories, manufacturers, procedures, forum, and training. Here, illustrative material on catheters, guidewires, coils, balloons, embolic protection, occlusion and closure devices, and stents and filters are available. Videos from several vendors on carotid stenting, central venous access, embolization, TIPSS, 
Table 1: Few review articles/citations on radiation

\begin{tabular}{|c|c|c|c|}
\hline Article/citation title & Author(s) & Year & Online detail of Journal with URL \\
\hline $\begin{array}{l}\text { The AAPM/RSNA Physics Tutorial for Residents: Typical } \\
\text { Patient Radiation Doses in Diagnostic Radiology }\end{array}$ & Parry RA et al. & 1999 & http://radiographics.rsna.org/content/19/5/1289.full.pdf \\
\hline $\begin{array}{l}\text { The AAPM/RSNA Physics Tutorial for Residents: Topics in } \\
\text { CT. Radiation dose in CT. }\end{array}$ & McNitt-Gray MF & 2002 & http://radiographics.rsnajnls.org/cgi/reprint/22/6/1541.pdf \\
\hline $\begin{array}{l}\text { Computed Tomography and Radiation Risks: What Pediatric } \\
\text { Health Care Providers Should Know }\end{array}$ & Frush DP, et al. & 2003 & http://pediatrics.aappublications.org/cgi/reprint/112/4/951.pdf \\
\hline Sustainability of medical imaging & Picano $\mathrm{E}$ & 2004 & http://www.bmj.com/cgi/reprint/328/7439/578 \\
\hline $\begin{array}{l}\text { Patient dose in multislice CT: Why is it increasing and does } \\
\text { it matter? }\end{array}$ & Dawson P & 2004 & http://bjr.birjournals.org/cgi/reprint/77/suppl_1/S10.pdf \\
\hline $\begin{array}{l}\text { What are the risks from medical X-rays and other low dose } \\
\text { radiation? }\end{array}$ & B F Wall et al. & 2006 & http://bjr.birjournals.org/cgi/reprint/79/940/285.pdf \\
\hline $\begin{array}{l}\text { An Investigation of Operator Exposure in Interventional } \\
\text { Radiology }\end{array}$ & Schueler BA & 2006 & http://radiographics.rsna.org/content/26/5/1533.full.pdf \\
\hline $\begin{array}{l}\text { Computed Tomography - An Increasing Source of Radiation } \\
\text { Exposure }\end{array}$ & Brenner DJ, Hall EJ & 2007 & http://content.nejm.org/cgi/reprint/357/22/2277.pdf \\
\hline $\begin{array}{l}\text { Radiation Exposure and Pregnancy: When Should We Be } \\
\text { Concerned? }\end{array}$ & McCollough CH et al. & 2007 & http://radiographics.rsna.org/content/27/4/909.full.pdf + html \\
\hline Imaging the Pregnant Patient for Nonobstetric Conditions & Patel SJ & 2007 & http://radiographics.rsna.org/content/27/6/1705.full.pdf \\
\hline Dose performance of a 64-channel dual-source CT scanner. & McCollough CH et al. & 2007 & http://radiology.rsna.org/content/243/3/775.full.pdf \\
\hline Radiation and your patient: A guide for medical practitioners & Committee 3 of ICRP & 2007 & http://www.icrp.org/docs/Rad_for_GP_for_web.pdf \\
\hline Radiation dose to patients from cardiac diagnostic imaging. & Einstein AJ et al. & 2007 & http://www.circ.ahajournals.org/cgi/reprint/116/11/1290.pdf \\
\hline $\begin{array}{l}\text { Radiation Dose-Reduction Strategies for Neuroradiology CT } \\
\text { Protocols }\end{array}$ & A.B. Smith et al. & 2007 & http://www.ajnr.org/cgi/reprint/28/9/1628.pdf \\
\hline Radiation Risk to Children From Computed Tomography & A. S. Brody et al. & 2007 & http://pediatrics.aappublications.org/cgi/reprint/120/3/677.pdf \\
\hline $\begin{array}{l}\text { American College of Radiology white paper on radiation dose } \\
\text { in medicine. }\end{array}$ & Amis ES Jr, et al. & 2007 & $\begin{array}{l}\text { http://www.acr.org/secondarymainmenucategories/quality_ } \\
\text { safety/white_paper_dose.aspx }\end{array}$ \\
\hline Cancer risks from diagnostic radiology & Hall EJ, Brenner D J & 2008 & http://bjr.birjournals.org/cgi/reprint/81/965/362.pdf \\
\hline Radiation Dose Reduction in Chest CT: A Review & Kubo T et al. & 2008 & http://www.ajronline.org/cgi/reprint/190/2/335.pdf \\
\hline $\begin{array}{l}\text { CT dosimetry: Comparison of measurement techniques and } \\
\text { devices. }\end{array}$ & Bauhs JA et al. & 2008 & http://radiographics.rsna.org/content/28/1/245.full.pdf \\
\hline $\begin{array}{l}\text { Radiation Dose Descriptors: BERT, COD, DAP, and Other } \\
\text { Strange Creatures }\end{array}$ & Nickoloff EL et al. & 2008 & http://radiographics.rsnajnls.org/cgi/reprint/28/5/1439.pdf \\
\hline $\begin{array}{l}\text { Effective doses in radiology and diagnostic nuclear } \\
\text { medicine: A catalog. }\end{array}$ & Mettler FA Jr et al. & 2008 & http://radiology.rsna.org/content/248/1/254.full.pdf \\
\hline $\begin{array}{l}\text { Radiation dose modulation techniques in the multidetector } \\
\text { CT era: From basics to practice. }\end{array}$ & Lee $\mathrm{CH}$ et al. & 2008 & http://radiographics.rsna.org/content/28/5/1451.full.pdf \\
\hline $\begin{array}{l}\text { New recommendations from the International Commission } \\
\text { on Radiological Protection—a review }\end{array}$ & Wrixon AD & 2008 & $\begin{array}{l}\text { http://www.iop.org/EJ/article/0031-9155/53/8/R01/pmb8_8_ } \\
\text { r01.pdf }\end{array}$ \\
\hline Ionizing Radiation in Cardiac Imaging: A Science Advisory & T. C. Gerber et al. & 2009 & $\begin{array}{l}\text { http://www.circ.ahajournals.org/cgi/reprint/ } \\
\text { CIRCULATIONAHA.108.191650v1.pdf }\end{array}$ \\
\hline $\begin{array}{l}\text { Estimated radiation dose associated with cardiac CT } \\
\text { angiography. }\end{array}$ & Hausleiter J et al. & 2009 & http://jama.ama-assn.org/cgi/reprint/301/5/500.pdf \\
\hline $\begin{array}{l}\text { Image Gently: Why We Should Talk to Parents About CT in } \\
\text { Children }\end{array}$ & Bulas et al. & 2009 & http://www.ajronline.org/cgi/reprint/192/5/1176.pdf \\
\hline
\end{tabular}

angioplasty, biliary drainage and stent insertion, nephrostomy, RF/cryoablation, chemo and radioembolization are available. Links to simulators, imaging equipment, contrast agents, and biopsy and drainage are also available.

MRI Acronym guides serve as handy tools, which tame the deluge of acronyms that is inherent to MRI technology and sequences. As of moment, the following acronym guides are available: Hitachi MRI Acronym Pocket Guide at http:// www.hitachimed.com/products/mri/MRIAcronymGuide/ index.html, Magnetic Resonance - Technology Information Portal: A Comparison of Acronyms at http://www.mr-tip. com/serv1.php?type = cam, IMAIOS MRI Acronym at http://www.e-mri.org/mri-sequences/acronyms.html and, lastly, the MRI Acronym Registration Service at http:// www.simplyphysics.com/MARS/Default.html.

Source of Support: Nil, Conflict of Interest: None declared. 